\title{
Chromosomal Alterations in Hepatocellular Nodules by Comparative Genomic Hybridization: High-Grade Dysplastic Nodules Represent Early Stages of Hepatocellular Carcinoma
}

\author{
Luigi Tornillo, Vincenza Carafa, Guido Sauter, Holger Moch, Ernesto Minola, \\ Marcello Gambacorta, Raffaela Vecchione, Leonardo Bianchi, and \\ Luigi M. Terracciano
}

Institute of Pathology (LT, VC, GS, HM, LB, LMT), University of Basel, Basel, Switzerland; and Department of Pathology, Ospedale Niguarda-Ca Granda (EM, MG), Milan, Department of Pathology (RV), University Federico II of Naples, Naples, and Unità Operativa Anatomia Patologica e Citopatologia Diagnostica (LT), Ospedale Oncologico, Rionero in Vulture $(P z)$, Italy

SUMMARY: Data from experimental hepatocarcinogenesis and recent studies in humans have suggested that the emergence of hepatocellular carcinoma $(\mathrm{HCC})$ is a stepwise process. However, despite abundant experimental data, the precise molecular mechanisms and genetic alterations involved in human liver carcinogenesis are still unclear. Comparative genomic hybridization was used to analyze 26 hepatocellular nodules obtained from patients undergoing liver transplantation or surgical resection for HCC. According to the criteria proposed by the International Working Party, 16 nodules were classified as multiacinar regenerative nodules (MRN), 4 as low-grade dysplastic nodules (LG-DN), and 6 as high-grade dysplastic nodules (HG-DN). Our aim was to investigate the possible genetic differences between MRN, LG-DN, and HG-DN. The whole group of nodules showed only a few aberrations (mean 1.1/case), without any significant pattern. This finding is comparable to what happens in non-neoplastic tissue. On the contrary, in three of six HG-DN, we found deletions of $8 p$ and gains of 1q. LG-DN and MRN did not show these chromosomal imbalances. These results confirm the important role of allelic losses on $8 p$ as well as of gains of $1 \mathrm{q}$ in HCC. We conclude that the genes that are important in early stages of hepatocarcinogenesis are probably located on these chromosomal arms. (Lab Invest 2002, 82:547-553).

H epatocellular carcinoma $(\mathrm{HCC})$ is one of the 1 most frequent neoplasias worldwide (Parkin et al, 1997), but the incidence of this tumor varies significantly in different geographical areas, with the highest incidence occurring in Sub-Saharan Africa and the Far East. The remarkable geographic variability of $\mathrm{HCC}$ is related to the variable prevalence of the environmental risk factors that play a critical role in liver carcinogenesis. Among these, hepatitis $B$ virus and hepatitis $C$ virus are by far the best-documented risk factors (Brechot et al, 1998; Moriya et al, 1998) implicated in the development of HCC. In Western countries and in Japan, most HCC develop from the morphologic setting of an active or inactive cirrhosis. There is growing evidence that liver cancerogenesis in cirrhosis is a multistep process. Because the prognosis of patients with HCC is extremely poor, the search for premalignant changes has gained an increasing interest in the last years. Early detection of small HCC is

Received November 19, 2001.

Address reprint requests to: Dr. Luigi M. Terracciano, Institute of Pathology, Schönbeinstrasse 40, Basel University Hospital, 4003 Basel, Switzerland.E-mail:lterracciano@ubbs.ch likely to represent the best way to achieve better therapeutic results.

However, morphologic and molecular features of premalignant hepatic lesions are far from being fully elucidated and uniformly accepted. Several lesions in the liver have been proposed to represent premalignant changes, but the exact nature of these possible HCC precursors is not understood. This uncertainty is reflected in the different classifications of preneoplastic lesions (Edmondson and Steiner, 1954; Eguchi et al, 1992; Ferrell et al, 1993; Furuya et al, 1988) and the continuous dispute on the various types and meanings of hepatic dysplasia (Anthony et al, 1973; Lee et al, 1997; Watanabe et al, 1983). In 1995 (IWP, 1995) an international study group proposed a classification of nodular hepatocellular lesions distinguishing regenerative lesions (multiacinar regenerative nodules; MRN) from neoplastic lesions. According to this classification, the neoplastic lesions encompass HCC and dysplastic nodules (DN), the latter including both lowgrade (LG-DN) and high-grade (HG-DN) categories. However the same group acknowledged that a strict line cannot be drawn between premalignant and malignant lesions and stated that "the most certain way 

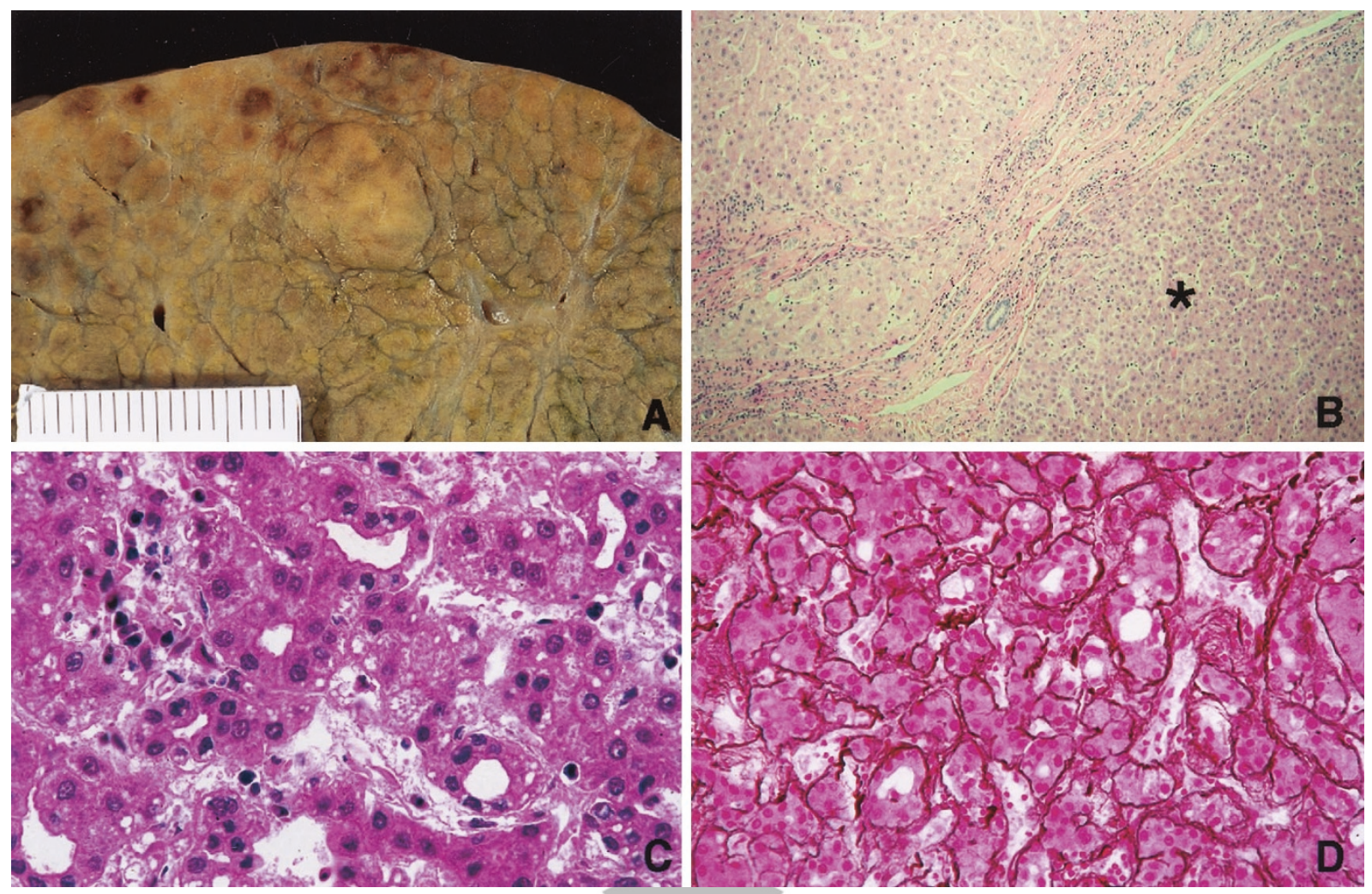

Figure 1.

Gross and microscopic characteristics of hepatocellular nodules. A, Macroscopic aspect of a dysplastic nodule. B, Low-grade dysplastic nodule (LG-DN; asterisk) in cirrhotic liver (top left). Hematoxylin and eosin, $\times 100$. C, High-grade dysplastic nodule (HG-DN) displaying pseudoglandular pattern and high nuclear/cytoplasmic ratio. Hematoxylin and eosin, $\times 400$. D, High-grade dysplastic nodule showing preserved reticulin pattern. Novotny, $\times 400$.

to make a diagnosis of dysplastic nodule is application of molecular genetic techniques" (IWP, 1995).

Recent studies have indicated that at least in a subset of cases, MRN and DN are indeed monoclonal (Paradis et al, 1998) and that their clonal expansion may be initiated before the full development of cirrhosis (Theise, 1995, 1996). Results of other molecular studies (Maggioni et al, 2000; Roncalli et al, 1999; Zondervan et al, 2000) are in keeping with the concept of a multistep process in hepatic carcinogenesis from cirrhosis to well-developed HCC. Several studies have shown that the oncogenes cyclin D1, c-myc, and transforming growth factor- $\alpha$ (Nishida et al, 1994; Thorgeirsson et al, 1996) and the tumor suppressor genes p16 (MTS1), p53, and Rb (Biden et al, 1997; Lunn et al, 1997; Zhang et al, 1994) are involved at least in subsets of HCC. Possible locations of other genes that might be critical for HCC development and progression have been implicated by molecular cytogenetic studies showing frequent allelic losses at $1 p$, $4 q, 6 q$, and $8 p$ as well as frequent gains at $1 q, 6 p, 8 q$, and 17q in HCC (Chen et al, 2000; Guan et al, 2000; Kusano et al, 1999; Marchio et al, 1997, 2000; Nagai et al, 1997; Piao et al, 1998; Pineau et al, 1999; Tornillo et al, 2000; Wong et al, 1999). Little is known, however, about the genomic alterations in possible HCC precursor lesions.

The aim of this study was to characterize chromosomal changes occurring in MRN, LG-DN, and HG-DN by comparative genomic hybridization (CGH) and to compare these findings with those previously reported in a series of HCC (Tornillo et al, 2000).

\section{Results}

All CGH alterations that were found in hepatocellular nodules are shown in Figure 2. Taken all together, hepatocellular nodules showed few aberrations, with no preferential pattern (mean 1.1/case). These results were similar to those observed in four nonneoplastic, cirrhotic specimens (1/case). However three of six cases of HG-DN showed gain of 1q (minimal overlapping region $1 q 32$-ter) and deletions of $8 p$. The LG-DN and MRN showed very few aberrations. $1 q+$ and $8 p-$ were not seen in LG-DN and MRN nor in cirrhotic tissues. Furthermore, in the LG-DN and HG-DN coming from the same liver explant, $1 q+$ and $8 p-$ were detected exclusively in the HG-DN. The difference in $1 \mathrm{q}+/ 8 \mathrm{p}-$ between HG-DN and LG-DN/MRN reached statistical significance $(p=0.002)$. A comparison of the present data with previous results (Tornillo et al, 2000) showed that the frequency of $1 q+$ and $8 p-$ in $\mathrm{HCC}$ is comparable to that in HG-DN (Table 2).

\section{Discussion}

Cirrhotic livers of patients with HCC have been shown to have increased numbers of genetic alterations as 
पIIIIIIIIII]

पImएवाID $x$

Drat

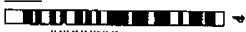

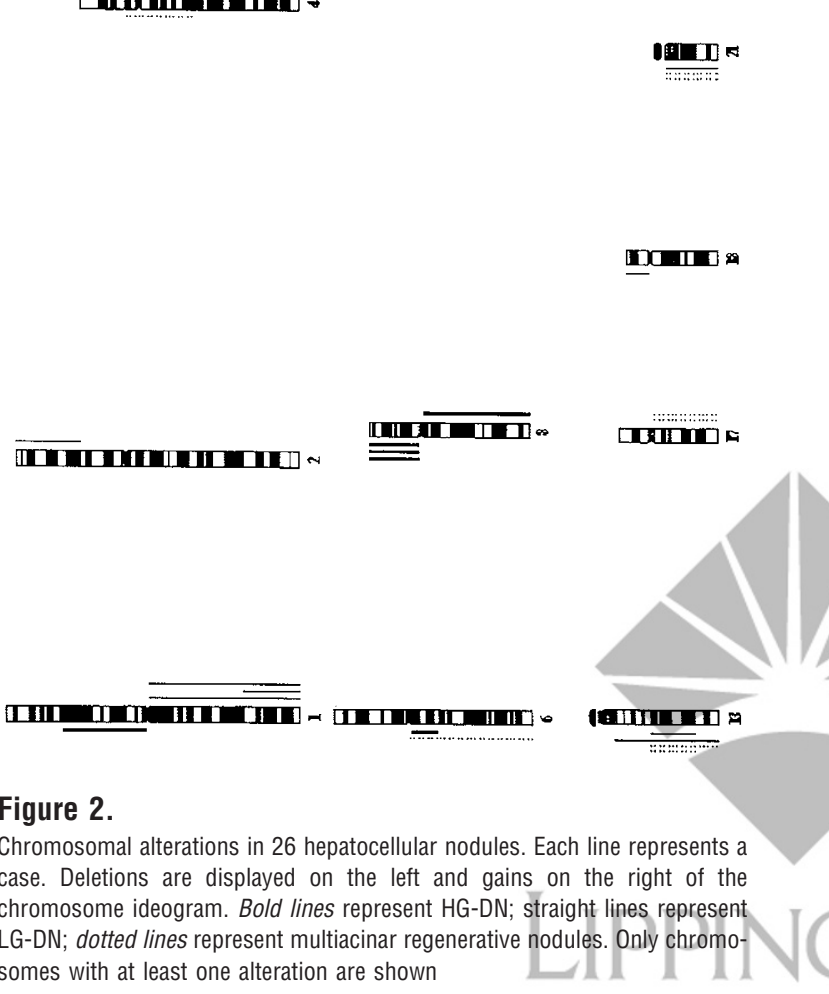

LG-DN; dotted lines represent multiacinar regenerative nodules. Only chromosomes with at least one alteration are shown

compared with HCC-free/cirrhosis (Roncalli et al, 2000). Cirrhosis has been considered in itself a preneoplastic condition (Okuda, 1992), while it has been shown that at least a subset of cirrhotic nodules may be monoclonal in origin (Aihara et al, 1994). Monoclonal neoplastic expansion could be initiated before the full development of cirrhosis (Theise, 1996). Therefore it could be speculated that cirrhosis progresses to cancer through a molecular pathway marked by sequential and additional genetic changes towards malignancy (Roncalli et al, 2000). There is no precise correspondence between genetic and morphologic alteration (IWP, 1995), so that the concept itself of hepatic dysplasia is still controversial. The original description of Anthony et al (1973) referred to what is today called "large cell dysplasia" (enlarged hepatocytes with nuclear pleomorphism and prominent nucleoli), a morphologic change that has been considered a reactive change (Lee et al, 1997; Su et al, 1997) or a sign of concurrent malignant neoplasia (Natarajan et al, 1997). On the other hand, a truly premalignant lesion seems to be represented by "small cell dysplasia" (Watanabe et al, 1983) (small hepatocytes with decreased, more basophilic cytoplasm and hyperchromatic nucleus), which shows phenotypic markers that are in favor of its precancerous nature (Su et al, 1997; Zhao et al, 1994a, 1994b).
In this study $\mathrm{CGH}$ was used to define molecular cytogenetic alterations in preneoplastic hepatic nodules. The comparison of the data with the results in non-neoplastic cirrhotic liver tissue and in HCC allowed us to define two distinct groups of preneoplastic lesions. MRN and LG-DN had very few alterations, similar to the background level found in cirrhotic tissue. The number of genomic alterations was clearly higher in HG-DN. In these nodules, the number and the type of chromosomal changes $(1 q+$ and $8 p-)$ were similar to those previously found in $\mathrm{HCC}$ by us and others (Kusano et al, 1999; Marchio et al, 1997, 2000; Tornillo et al, 2000; Wong et al, 1999). These observations provide strong evidence for the assumption that HG-DN are immediate HCC precursor lesions, with a high risk of progression, and therefore should be treated accordingly. The results are consistent with observations made in previous studies suggesting major biologic differences between LG-DN and HG-DN on the basis of vascular profile of the different types (Park et al, 1998; Roncalli et al, 1999; Terada and Nakanuma, 1995).

$8 p$ - is one of the major alterations in liver cancer (Chen et al, 2000; Guan et al, 2000; Kusano et al, 1999; Maggioni et al, 2000; Marchio et al, 1997, 2000; Tornillo et al, 2000; Wong et al, 1999). In many tumor types, microsatellite studies have detected at least three different regions of allelic loss on $8 p$, suggesting the presence of several tumor suppressor genes located on 8p21, 8p22, and 8p23 (Lerebours et al, 1999; Pineau et al, 1999; Wright et al, 1998). 8p has also been shown to be a site of preferential loss of heterozygosity in a series of hepatocellular nodules, with increasing frequency from cirrhosis to HCC (Maggioni et $\mathrm{al}, 2000$ ). As in our study, Maggioni et al (2000) could not detect significant differences between HG-DN and HCC. Candidate tumor suppressor genes located on chromosome $8 p$ may be FEZ1, a recently described cancer-related leucine zipper motif gene that showed altered expression in multiple tumor types (Ishii et al, 1999). 8p - has also been suggested to play a role in tumor progression in HCC (Boige et al, 1997; Guan et al, 2000) as well as in oral (Ishwad et al, 1999), renal (Schullerus et al, 1999), and breast carcinoma (Radford et al, 1995). $8 p$ - is often found together with $8 \mathrm{q}+$, a finding that is normally interpreted as an isochromosome 8q (Mertens et al, 1997). Marchio et al (2000) have recently reported a series of non-virus-associated HCC in which $30 \%$ of $8 p$ - were not balanced by a symmetric gain of $8 \mathrm{q}$. The observation that $8 p-$ was only associated with $8 q+$ in one of three of our HG-DN would also be consistent with inactivation of a tumor suppressor gene on $8 p-$ preceding overexpression of genes on $8 \mathrm{q}$.

Recently Zondervan et al (2000) investigated 12 hepatic dysplastic areas adjacent to HCC by CGH without detecting $8 p$ losses. However, the lower frequency of alteration found in this study may be a result of a high frequency of LG-DN in their set of nodules because no information was given on the degree of dysplasia in these DN. 
Table 1. Clinico-Pathologic Characteristics of 26 Hepatocellular Nodules

\begin{tabular}{lcc}
\hline & Patients & Nodules \\
\hline Total & 17 & 26 \\
M/F & $10 / 7$ & $17 / 9$ \\
Mean age & $49.3( \pm 4.3)$ & 49 \\
Mean size & 1.3 & $1.3( \pm 0.2)$ \\
HBV & 9 & 12 \\
HCV & 8 & 14 \\
HCC & 8 & 12 \\
MRN $(\mathrm{HCC}+)^{a}$ & $12(3)$ & $16(5)$ \\
LG-DN $(\mathrm{HCC}+)^{a}$ & $3(1)$ & $4(2)$ \\
HG-DN $(\mathrm{HCC}+)^{a}$ & $5(4)$ & $6(5)$ \\
\hline
\end{tabular}

In six patients more than one nodule was examined.

${ }^{a} \mathrm{HCC}+, \mathrm{HCC}$ was present in other areas of the resection specimen.

M, male; F, female; HBV, hepatitis B virus; HCV, hepatitis C virus; HCC, hepatocellular carcinoma; MRN, multiacinar regenerative nodules; LG-DN, low-grade dysplastic nodules; HG-DN, high-grade dysplastic nodules.

Gains of 1q have been described in many tumors (Mertens et al, 1997). Previous studies in bladder cancer have shown recurrent high-level amplification in the pericentromeric region of $1 \mathrm{q}$, suggesting involvement of an as yet unknown oncogene in this area (Richter et al, 1997, 1999). Circumscribed high-level amplifications have not been found in HCC. In most cases low-level gains of entire 1q were seen (Guan et al, 2000; Kusano et al, 1999; Marchio et al, 1997, 2000; Tornillo et al, 2000; Wong et al, 1999, 2001). It is therefore possible that a simultaneous overexpression of multiple genes on $1 \mathrm{q}$ can provide a growth advantage to neoplastic liver cells. Recently Wong et al (2001) have reported that hypomethylation of band $1 \mathrm{q} 12$ is strictly related to aberrant $1 \mathrm{q}$ formation in HCC. Therefore the heterochromatin fragility could result in the clonal evolution of cells with extra copies of $1 \mathrm{q}$ and may confer proliferative advantages to these clones. However, it seems more possible that the actual target genes are still undiscovered, given the small fraction of known genes as compared with the estimated total number of about 30,000 genes (Venter et al, 2001).

In summary, the results of this study suggest that HG-DN are tightly related to HCC based on the molecular cytogenetic profile. $8 p-$ and $1 q+$ are the most common alterations in HG-DN and HCC. Because none of these changes were found in LG-DN or cirrhotic liver tissue, it is possible that the molecular examination of these loci might be helpful in the difficult distinction between LG-DN and HG-DN in biopsy material.

\section{Materials and Methods}

\section{Specimens}

Twenty-six formalin-fixed, paraffin-embedded hepatocellular nodules from 21 patients were retrieved from the files of the Institutes of Pathology of Naples, Milan, and Basel. The clinicopathologic characteristics of the lesions are summarized in Table 1. Sixteen nodules were classified as MRN, four as LG-DN, and six as HG-DN. The hepatitis B virus +/hepatitis $C$ virus + ratio was three of three for HG-DN, one of three for LG-DN, and eight of eight for MRN. Moreover in one case, we were able to analyze a LG-DN and an HG-DN from the same liver explant. In addition, four specimens of cirrhotic, nonneoplastic tissue were examined as controls. MRN and dysplastic nodules were defined grossly and microscopically following the criteria and nomenclature of the International Working Party (IWP, 1995). All MRN were larger than $0.5 \mathrm{~cm}$ in diameter (mean, 1.2; range, 0.9 to $1.5 \mathrm{~cm}$ ) and surrounded by a condensed rim of fibrous tissue. Portal structures were distributed throughout the lesion. Grossly, dysplastic nodules were lesions distinct from the surrounding liver parenchyma in size, color, texture, or degree of bulge beyond the cut surface of the surrounding liver (Fig. 1A). Histologically, dysplastic nodules were classified as low grade (showing normal architecture and mild cytologic atypia) (Fig. 1B) or high grade (containing architectural and severe cytologic atypia) (Fig. 1, C and D).

\section{DNA Preparation}

All nodule blocks were trimmed to enrich for tumor. Fifteen $10-\mu \mathrm{m}$ thick sections were taken for DNA extraction. The first and the last sections were stained with hematoxylin and eosin. Nodules having an average tumor cell content of less than $75 \%$ in these sections were excluded. DNA extraction and labeling was as described (Kallioniemi et al, 1992). Sections were deparaffinized and suspended in DNA extraction buffer containing $0.5 \mathrm{mg} / \mathrm{ml}$ proteinase $\mathrm{K}$. Additional proteinase $\mathrm{K}$ was added at 24 and 48 hours, for a total incubation time of 72 hours. One microgram of tumor DNA was nick translated by using a commercial kit (BioNick kit; Invitrogen, Carlsbad, California) and Spectrum Green-dUTPs (Vysis Inc., Downers Grove, Illinois) for direct labeling of tumor DNA. Spectrum Red-labeled normal reference DNA (Vysis) was used for cohybridization.

\section{CGH and Digital Image Analysis}

The hybridization mixture consisted of $200 \mathrm{ng}$ of Spectrum Green-labeled tumor DNA, 200 ng of Spectrum Red-labeled normal reference DNA, and $20 \mu \mathrm{g}$ of Cot-1 DNA (Invitrogen) dissolved in $10 \mu$ l of hybridization buffer $(50 \%$ formamide, $10 \%$ dextran sulfate, $2 \times$ SSC, pH 7.0). Hybridization was for 3 days at $37^{\circ} \mathrm{C}$ to normal metaphase spreads (Vysis). Posthybridization washes were as described (Kallioniemi et al, 1992). Digital images (4,6-diamidino-2-phenylindol, FITC, and Texas Red) were collected from four to six metaphases using a Photometrics cooled CCD camera (Microimager 1400; Xillix Technologies, Vancouver, British Columbia, Canada) and a Sun workstation. The Vysis software program was used to calculate average green to red ratio profiles for each chromosome. At least four observations per autosome and two obser- 
Table 2. Most Important Alterations Found in Hepatocellular Nodules and HCCs

\begin{tabular}{lcllr}
\hline & MRN & \multicolumn{1}{c}{ LG-DN } & HG-DN & HCC $^{a}$ \\
\hline $\mathrm{N}$ & 16 & 4 & 6 & 41 \\
Deletions & $8(0.5 /$ case $)$ & $3(0.7 /$ case $)$ & $6(1 /$ case $)$ & $189(4.6 /$ case $)$ \\
Gains & $3(0.2 /$ case $)$ & $2(0.5 /$ case $)$ & $6(1 /$ case $)$ & $105(2.5 /$ case $)$ \\
Total & $11(0.7 /$ case $)$ & $5(1.2 /$ case $)$ & $12(2 /$ case $)$ & $296(7.2 /$ case $)$ \\
$1 q+$ & 0 & 0 & $3(50 \%)$ & $19(46 \%)$ \\
$8 p-$ & 0 & 0 & $3(50 \%)$ & $18(44 \%)$ \\
$4 q-$ & 1 & 0 & 0 & $16(39 \%)$ \\
$9 p-$ & 0 & 0 & 0 & $9(22 \%)$ \\
$6 q-$ & 0 & $1(25 \%)$ & $1(16 \%)$ & $15(37 \%)$ \\
$13 q-$ & 2 & $1(25 \%)$ & $1(16 \%)$ & $16(39 \%)$ \\
$6 p+$ & 0 & 0 & 0 & $8(20 \%)$ \\
$8 q+$ & 0 & 0 & $1(16 \%)$ & $17(42 \%)$ \\
$17 q+$ & 2 & 0 & 0 & $15(37 \%)$ \\
\hline
\end{tabular}

${ }^{a}$ Data from Tornillo et al, 2000.

MRN, multiacinar regenerative nodules; LG-DN, low-grade dysplastic nodules; HG-DN, high-grade dysplastic nodules; HCC, hepatocellular carcinoma.

vations per sex chromosome were included in each analysis.

\section{Controls and Threshold Definition}

Each CGH experiment included a tumor cell line (Spectrum Green MPE-600; Vysis) with known aberrations (positive control) and a hybridization of two differentially labeled sex-mismatched normal DNAs to each other (negative control). Moreover, we performed $\mathrm{CGH}$ on nontumoral liver. Sex-mismatched normal controls were used to test the ability of each metaphase batch to allow for a linear relationship between fluorescence intensities and DNA sequence copy numbers. Metaphases were only used if the color ratio of sex-mismatched normal DNAs was $\leq 0.66$ at the $X$ chromosome. Thresholds used for definition of DNA sequence copy number gains and losses were based on the results of $\mathrm{CGH}$ analyses of formalin-fixed normal tissues. A gain of DNA sequences was assumed at chromosomal regions where the hybridization resulted in a tumor to normal ratio $\geq 1.20$. Overrepresentations were considered amplifications when the fluorescence ratio values exceeded 1.5 in a subregion of a chromosome arm. A loss of DNA sequences was presumed at chromosomal regions where the tumor to normal ratio was $<0.80$. To define an aberration, it was additionally required that the first standard deviation was above (gain) or below (deletion) 1.00 .

\section{Statistical Analysis}

Chromosomal alterations were compared between various groups by the $\chi^{2}$ test with Fisher's correction for continuity.

\section{References}

Aihara T, Noguchi S, Sasaki Y, Nakano H, and Imaoka S (1994). Clonal analysis of regenerative nodules in hepatitis C virus-induced liver cirrhosis. Gastroenterology 107:18051811.
Anthony PP, Vogel CL, and Barker LF (1973). Liver cell dysplasia: A premalignant condition. J Clin Pathol 26:217223.

Biden K, Young J, Buttenshaw R, Searle J, Cooksley G, Xu $D B$, and Leggett B (1997). Frequency of mutation and deletion of the tumor suppressor gene CDKN2A (MTS1/p16) in hepatocellular carcinoma from an Australian population. Hepatology 25:593-597.

Boige V, Laurent-Puig P, Fouchet P, Flejou JF, Monges G, Bedossa $P$, Bioulac-Sage $P$, Capron F, Schmitz A, Olschwang S, and Thomas G (1997). Concerted nonsyntenic allelic losses in hyperploid hepatocellular carcinoma as determined by a high-resolution allelotype. Cancer Res 57: 1986-1990.

Brechot C/Jaffredo F, Lagorce D, Gerken G, Meyer zum Buschenfelde K, Papakonstontinou A, Hadziyannis S, Romeo R, Colombo M, Rodes J, Bruix J, Williams R, and Naoumov N (1998). Impact of HBV, HCV and GBV-C/HGV on hepatocellular carcinomas in Europe: Results of a European concerted action. J Hepatol 29:173-183.

Chen YJ, Yeh SH, Chen JT, Wu CC, Hsu MT, Tsai SF, Chen PJ, and Lin CH (2000). Chromosomal changes and clonality relationship between primary and recurrent hepatocellular carcinoma. Gastroenterology 119:431-440.

Edmondson $\mathrm{H}$ and Steiner $\mathrm{P}$ (1954). Primary carcinoma of the liver: A study of 100 cases among 48900 necropsies. Cancer 1:462-503.

Eguchi A, Nakashima O, Okudaira S, Sugihara S, and Kojiro $M$ (1992). Adenomatous hyperplasia in the vicinity of small hepatocellular carcinoma. Hepatology 15:843-848.

Ferrell LD, Crawford JM, Dhillon AP, Scheuer PJ, and Nakanuma $Y$ (1993). Proposal for standardized criteria for the diagnosis of benign, borderline, and malignant hepatocellular lesions arising in chronic advanced liver disease. Am J Surg Pathol 17:1113-1123.

Furuya K, Nakamura M, Yamamoto Y, Togei K, and Otsuka H (1988). Macroregenerative nodule of the liver: A clinicopathologic study of 345 autopsy cases of chronic liver disease. Cancer 61:99-105.

Guan XY, Fang Y, Sham JS, Kwong DL, Zhang Y, Liang Q, Li $\mathrm{H}$, Zhou H, and Trent JM (2000). Recurrent chromosome 
alterations in hepatocellular carcinoma detected by comparative genomic hybridization. Genes Chromosomes Cancer 29:110-116.

Ishii H, Baffa R, Numata SI, Murakumo Y, Rattan S, Inoue H, Mori M, Fidanza V, Alder H, and Croce CM (1999). The FEZ1 gene at chromosome 8p22 encodes a leucine-zipper protein, and its expression is altered in multiple human tumors. Proc Natl Acad Sci USA 96:3928-3933.

Ishwad CS, Shuster M, Bockmuhl U, Thakker N, Shah P, Toomes C, Dixon M, Ferrell RE, and Gollin SM (1999). Frequent allelic loss and homozygous deletion in chromosome band 8p23 in oral cancer. Int J Cancer 80:25-31.

IWP (1995). Terminology of nodular hepatocellular lesions. Hepatology 22:983-993.

Kallioniemi A, Kallioniemi OP, Sudar D, Rutovitz D, Gray JW, Waldman F, and Pinkel D (1992). Comparative genomic hybridization for molecular cytogenetic analysis of solid tumors. Science 258:818-821.

Kusano N, Shiraishi K, Kubo K, Oga A, Okita K, and Sasaki K (1999). Genetic aberrations detected by comparative genomic hybridization in hepatocellular carcinomas: Their relationship to clinicopathological features. Hepatology 29: 1858-1862.

Lee RG, Tsamandas AC, and Demetris AJ (1997). Large cell change (liver cell dysplasia) and hepatocellular carcinoma in cirrhosis: Matched case-control study, pathological analysis, and pathogenetic hypothesis. Hepatology 26:1415-1422.

Lerebours F, Olschwang S, Thuille B, Schmitz A, Fouchet P, Buecher B, Martinet N, Galateau F, and Thomas G (1999). Fine deletion mapping of chromosome $8 p$ in non-small-cell lung carcinoma. Int J Cancer 81:854-858.

Lunn RM, Zhang YJ, Wang LY, Chen CJ, Lee PH, Lee CS, Tsai WY, and Santella RM (1997). p53 mutations, chronic hepatitis $B$ virus infection, and aflatoxin exposure in hepatocellular carcinoma in Taiwan. Cancer Res 57:3471-3477.

Maggioni M, Coggi G, Cassani B, Bianchi P, Romagnoli S, Mandelli A, Borzio M, Colombo P, and Roncalli M (2000). Molecular changes in hepatocellular dysplastic nodules on microdissected liver biopsies. Hepatology 32:942-946.

Marchio A, Meddeb M, Pineau P, Danglot G, Tiollais P, Bernheim A, and Dejean A (1997). Recurrent chromosomal abnormalities in hepatocellular carcinoma detected by comparative genomic hybridization. Genes Chromosomes Cancer 18:59-65.

Marchio A, Pineau P, Meddeb M, Terris B, Tiollais P, Bernheim $A$, and Dejean $A$ (2000). Distinct chromosomal abnormality pattern in primary liver cancer of non-B, non-C patients. Oncogene 19:3733-3738.

Mertens F, Johansson B, Hoglund M, and Mitelman F (1997). Chromosomal imbalance maps of malignant solid tumors: A cytogenetic survey of 3185 neoplasms. Cancer Res 57:27652780 .

Moriya K, Fujie H, Shintani Y, Yotsuyanagi H, Tsutsumi T, Ishibashi K, Matsuura Y, Kimura S, Miyamura T, and Koike K (1998). The core protein of hepatitis $C$ virus induces hepatocellular carcinoma in transgenic mice. Nat Med 4:1065-1067.

Nagai $H$, Pineau $P$, Tiollais $P$, Buendia MA, and Dejean A (1997). Comprehensive allelotyping of human hepatocellular carcinoma. Oncogene 14:2927-2933.
Natarajan S, Theise ND, Thung SN, Antonio L, Paronetto F, and Hytiroglou P (1997). Large-cell change of hepatocytes in cirrhosis may represent a reaction to prolonged cholestasis. Am J Surg Pathol 21:312-318.

Nishida N, Fukuda Y, Komeda T, Kita R, Sando T, Furukawa M, Amenomori M, Shibagaki I, Nakao K, Ikenaga M, and Ishizaki K (1994) Amplification and overexpression of the cyclin D1 gene in aggressive human hepatocellular carcinoma. Cancer Res 54:3107-3110.

Okuda K (1992). Hepatocellular carcinoma: Recent progress. Hepatology 15:948-963.

Paradis V, Laurendeau I, Vidaud M, and Bedossa P (1998). Clonal analysis of macronodules in cirrhosis. Hepatology 28:953-958.

Park YN, Yang CP, Fernandez GJ, Cubukcu O, Thung SN, and Theise ND (1998). Neoangiogenesis and sinusoidal "capillarization" in dysplastic nodules of the liver. Am J Surg Pathol 22:656-662.

Parkin DM, Whelan SL, Ferlay J, Raymond L, and Young J, editors (1997). Cancer incidence in five continents. Lyon: IARC Scientific Publications.

Piao Z, Park C, Park JH, and Kim H (1998). Allelotype analysis of hepatocellular carcinoma. Int J Cancer 75:29-33.

Pineau P, Nagai H, Prigent S, Wei Y, Gyapay G, Weissenbach J, Tiollais P, Buendia MA, and Dejean A (1999). Identification of three distinct regions of allelic deletions on the short arm of chromosome 8 in hepatocellular carcinoma. Oncogene 18: 3127-3134.

Radford DM, Fair KL, Phillips NJ, Ritter JH, Steinbrueck T, Holt MS, and Donis-Keller H (1995). Allelotyping of ductal carcinoma in situ of the breast: Deletion of loci on 8p, 13q, 16q, 17p and 17q. Cancer Res 55:3399-3405.

Richter J, Jiang F, Gorog JP, Sartorius G, Egenter C, Gasser TC, Moch H, Mihatsch MJ, and Sauter G (1997). Marked genetic differences between stage pTa and stage pT1 papillary bladder cancer detected by comparative genomic hybridization. Cancer Res 57:2860-2864.

Richter J, Wagner U, Schraml P, Maurer R, Alund G, Knonagel H, Moch H, Mihatsch MJ, Gasser TC, and Sauter G (1999). Chromosomal imbalances are associated with a high risk of progression in early invasive (pT1) urinary bladder cancer. Cancer Res 59:5687-5691.

Roncalli M, Bianchi P, Grimaldi GC, Ricci D, Laghi L, Maggioni M, Opocher E, Borzio M, and Coggi G (2000). Fractional allelic loss in non-end-stage cirrhosis: Correlations with hepatocellular carcinoma development during follow-up. Hepatology 31:846-850.

Roncalli M, Roz E, Coggi G, Di Rocco MG, Bossi P, Minola E, Gambacorta M, and Borzio M (1999). The vascular profile of regenerative and dysplastic nodules of the cirrhotic liver: Implications for diagnosis and classification. Hepatology 30:1174-1178.

Schullerus D, von Knobloch R, Chudek J, Herbers J, and Kovacs $G$ (1999). Microsatellite analysis reveals deletion of a large region at chromosome $8 p$ in conventional renal cell carcinoma. Int J Cancer 80:22-24.

Su Q, Benner A, Hofmann WJ, Otto G, Pichlmayr R, and Bannasch P (1997). Human hepatic preneoplasia: Phenotypes and proliferation kinetics of foci and nodules of altered hepatocytes and their relationship to liver cell dysplasia. Virchows Arch 431:391-406. 
Terada $T$ and Nakanuma $Y$ (1995). Arterial elements and perisinusoidal cells in borderline hepatocellular nodules and small hepatocellular carcinomas. Histopathology 27:333339.

Theise ND (1995). Macroregenerative (dysplastic) nodules and hepatocarcinogenesis: Theoretical and clinical considerations. Semin Liver Dis 15:360-371.

Theise ND (1996). Cirrhosis and hepatocellular neoplasia: More like cousins than like parent and child. Gastroenterology 111:526-528.

Thorgeirsson UP, Gomez DE, Lindsay CK, Sinha CC, and Adamson RH (1996). Liver tumors and possible preneoplastic lesions, induced by a food-derived heterocyclic amine in cynomolgus monkeys: A study of histology and cytokeratin expression. Liver 16:71-83.

Tornillo L, Carafa V, Richter J, Sauter G, Moch H, Minola E, Gambacorta M, Bianchi L, Vecchione R, and Terracciano LM (2000). Marked genetic similarities between hepatitis B viruspositive and hepatitis $\mathrm{C}$ virus-positive hepatocellular carcinomas. J Pathol 192:307-312.

Venter JC, Adams MD, Myers EW, Li PW, Mural RJ, Sutton GG, Smith HO, Yandell M, Evans CA, Holt RA, Gocayne JD, Amanatides P, Ballew RM, Huson DH, Wortman JR, Zhang Q, Kodira CD, Zheng XH, Chen L, Skupski M, Subramanian G, Thomas PD, Zhang J, Gabor Miklos GL, Nelson C, Broder S, Clark AG, Nadeau J, McKusick VA, Zinder N, Levine AJ, Roberts RJ, Simon M, Slayman C, Hunkapiller M, Bolanos R, Delcher A, Dew I, Fasulo D, Flanigan M, Florea L, Halpern A, Hannenhalli S, Kravitz S, Levy S, Mobarry C, Reinert K, Remington K, Abu-Threideh J, Beasley E, Biddick K, Bonazzi V, Brandon R, Cargill M, Chandramouliswaran I, Charlab R, Chaturvedi K, Deng Z, Di Francesco V, Dünn P, Eilbeck K, Evangelista C, Gabrielian AE, Gan W, Ge W, Gong F, Gu Z, Guan P, Heiman TJ, Higgins ME, Ji RR, Ke Z, Ketchum KA, Lai Z, Lei Y, Li Z, Li J, Liang Y, Lin X, Lu F, Merkulov GV, Milshina N, Moore HM, Naik AK, Narayan VA, Neelam B, Nusskern D, Rusch DB, Salzberg S, Shao W, Shue B, Sun J, Wang Z, Wang A, Wang X, Wang J, Wei M, Wides R, Xiao C, et al (2001). The sequence of the human genome. Science 291:1304-1351.
Watanabe S, Okita K, Harada T, Kodama T, Numa Y, Takemoto T, and Takahashi T (1983). Morphologic studies of the liver cell dysplasia. Cancer 51:2197-205.

Wong N, Lai P, Lee SW, Fan S, Pang E, Liew CT, Sheng Z, Lau JW, and Johnson PJ (1999). Assessment of genetic changes in hepatocellular carcinoma by comparative genomic hybridization analysis: Relationship to disease stage, tumor size, and cirrhosis. Am J Pathol 154:37-43.

Wong N, Lam WC, Lai PB, Pang E, Lau WY, and Johnson PJ (2001). Hypomethylation of chromosome 1 heterochromatin DNA correlates with q-arm copy gain in human hepatocellular carcinoma. Am J Pathol 159: 465-471.

Wright K, Wilson PJ, Kerr J, Do K, Hurst T, Khoo SK, Ward B, and Chenevix-Trench G (1998). Frequent loss of heterozygosity and three critical regions on the short arm of chromosome 8 in ovarian adenocarcinomas. Oncogene 17:11851188.

Zhang X, Xu HJ, Murakami Y, Sachse R, Yashima K, Hirohashi S, Hu SX, Benedict WF, and Sekiya T (1994). Deletions of chromosome $13 \mathrm{q}$, mutations in retinoblastoma 1 , and retinoblastoma protein state in human hepatocellular carcinoma. Cancer Res 54:4177-4182.

Zhao M, Zhang NX, Du ZY, Laissue JA, and Zimmermann A (1994a). Three types of liver cell dysplasia (LCD) in small cirrhotic nodules are distinguishable by karyometry and PCNA labelling, and their features resemble distinct grades of hepatocellular carcinoma. Histol Histopathol 9:73-83.

Zhao M, Zhang NX, Economou M, Blaha I, Laissue JA, and Zimmermann A (1994b). Immunohistochemical detection of bcl-2 protein in liver lesions: bcl-2 protein is expressed in hepatocellular carcinomas but not in liver cell dysplasia. Histopathology 25:237-245.

Zondervan PE, Wink J, Alers JC, IJzermans JN, Schalm SW, de Man RA, and van Dekken H (2000). Molecular cytogenetic evaluation of virus-associated and non-viral hepatocellular carcinoma: Analysis of 26 carcinomas and 12 concurrent dysplasias. J Pathol (192):207-215. 